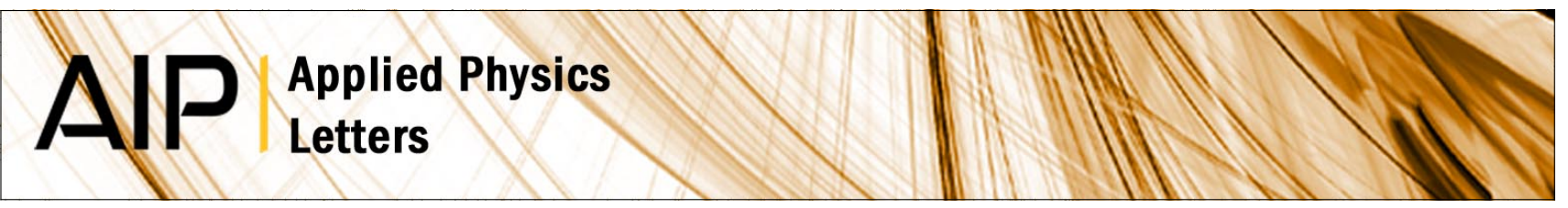

\title{
Highly (111)-oriented Ge thin films on insulators formed by Al-induced crystallization
}

K. Toko, M. Kurosawa, N. Saitoh, N. Yoshizawa, N. Usami et al.

Citation: Appl. Phys. Lett. 101, 072106 (2012); doi: 10.1063/1.4744962

View online: http://dx.doi.org/10.1063/1.4744962

View Table of Contents: http://apl.aip.org/resource/1/APPLAB/v101/i7

Published by the American Institute of Physics.

\section{Related Articles}

Impact of atomic layer deposition temperature on $\mathrm{HfO} 2 / \mathrm{InGaAs}$ metal-oxide-semiconductor interface properties J. Appl. Phys. 112, 084103 (2012)

Method for investigating threshold field of charge injection at electrode/dielectric interfaces by space charge observation

Appl. Phys. Lett. 101, 172902 (2012)

An accurate characterization of interface-state by deep-level transient spectroscopy for Ge metal-insulatorsemiconductor capacitors with $\mathrm{SiO} 2 / \mathrm{GeO} 2$ bilayer passivation

J. Appl. Phys. 112, 083707 (2012)

Electron transport properties of carbon nanotube-graphene contacts

Appl. Phys. Lett. 101, 153501 (2012)

Response to "Comment on 'Broadening of metal-oxide-semiconductor admittance characteristics: Measurement, sources, and its effects on interface state density analyses'" [J. Appl. Phys. 112, 076101 (2012)]

J. Appl. Phys. 112, 076102 (2012)

\section{Additional information on Appl. Phys. Lett.}

Journal Homepage: http://apl.aip.org/

Journal Information: http://apl.aip.org/about/about_the_journal

Top downloads: http://apl.aip.org/features/most_downloaded

Information for Authors: http://apl.aip.org/authors

\section{ADVERTISEMENT}
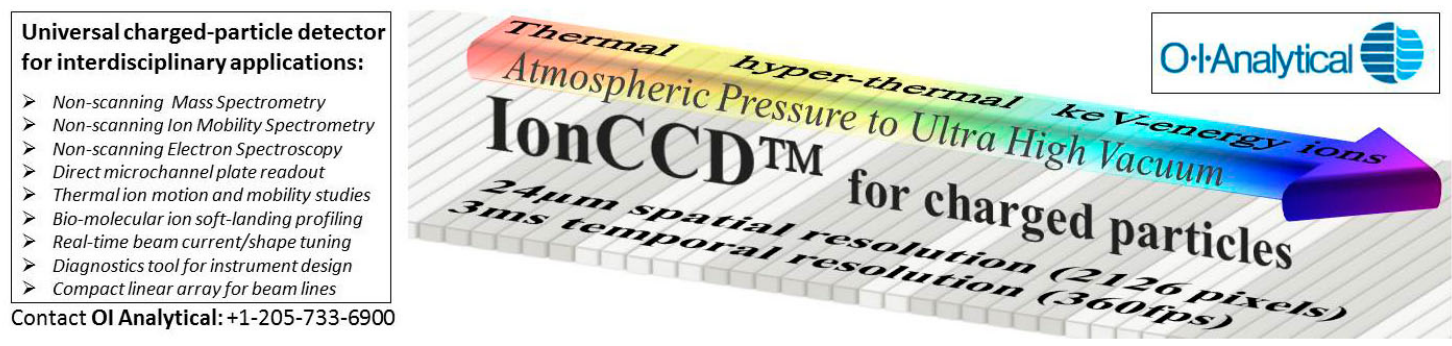


\title{
Highly (111)-oriented Ge thin films on insulators formed by Al-induced crystallization
}

\author{
K. Toko, ${ }^{1, a)}$ M. Kurosawa, ${ }^{2}$ N. Saitoh, ${ }^{3}$ N. Yoshizawa, ${ }^{3}$ N. Usami, ${ }^{4}$ M. Miyao, ${ }^{2}$ \\ and T. Suemasu ${ }^{1}$ \\ ${ }_{1}^{1}$ Institute of Applied Physics, University of Tsukuba, Tsukuba, Ibaraki 305-8573, Japan \\ ${ }^{2}$ Department of Electronics, Kyushu University, Motooka, Fukuoka 819-0395, Japan \\ ${ }^{3}$ Electron Microscope Facility, IBEC Innovation Platform, AIST, 16-1 Onogawa, Tsukuba 305-8569, Japan \\ ${ }^{4}$ Institute for Materials Research, Tohoku University, Sendai, Miyagi 980-8577, Japan
}

(Received 28 June 2012; accepted 26 July 2012; published online 16 August 2012)

\begin{abstract}
(111)-oriented Ge thin films on insulators are essential for advanced electronics and photovoltaic applications. We investigate Al-induced crystallization of amorphous-Ge films (50-nm thickness) on insulators focusing on the annealing temperature and the diffusion controlling process between $\mathrm{Ge}$ and $\mathrm{Al}$. The (111)-orientation fraction of the grown Ge layer reaches as high as $99 \%$ by combining the low-temperature annealing $\left(325^{\circ} \mathrm{C}\right)$ and the native-oxidized $\mathrm{Al}\left(\mathrm{AlO}_{\mathrm{x}}\right)$ diffusioncontrol layer. Moreover, the transmission electron microscopy reveals the absence of defects on the Ge surface. This (111)-oriented Ge on insulators promises to be the high-quality epitaxial template for various functional materials to achieve next-generation devices. () 2012 American Institute of Physics. [http://dx.doi.org/10.1063/1.4744962]
\end{abstract}

The high-quality crystalline Ge thin-film on insulators has versatile applications, such as thin-film transistors, highly efficient solar cells, and three-dimensional on-chip optical interconnects. ${ }^{1-3}$ In particular, (111)-oriented Ge provides the highest carrier mobility of Ge transistors and acts as the epitaxial templates for Ge nanowires or spintronics materials. ${ }^{4-6}$ These applications also require the lowtemperature process to avoid softening glass substrates $\left(<550^{\circ} \mathrm{C}\right)$ or breaking underlying integrated circuits $\left(<400^{\circ} \mathrm{C}\right)$. Many researchers have developed the advanced growth techniques: metal-induced solid-phase crystallization (SPC), laser annealing, and chemical-vapor deposition (CVD). ${ }^{7-9}$ However, the grown Ge layers consisted of small grains $(<\mu \mathrm{m})$ with almost random orientations.

Aluminum-induced crystallization (AIC) is one of the metal-induced SPC techniques developed for amorphous-Si (a-Si) films on glass substrates. ${ }^{10-15}$ This AIC technique enables us to form large-grain (diameters: $10-100 \mu \mathrm{m}$ ) polycrystalline Si films at relativity low temperatures $\left(420-550^{\circ} \mathrm{C}\right)$ through the exchange between the $\mathrm{Al}$ and $\mathrm{Si}$ layers during annealing. ${ }^{10-15}$ Moreover, we controlled the orientations of the Al-induced-crystallized Si (AIC-Si) films to either (100) or (111) plane by modulating the annealing temperatures, the thickness of $\mathrm{Al}$ and $\mathrm{Si}$ layers, and the thickness of $\mathrm{Al}$ native oxide $\left(\mathrm{AlO}_{\mathrm{x}}\right)$ interlayers between $\mathrm{Si}$ and $\mathrm{Al}$ layers. ${ }^{13-15} \mathrm{CVD}$ of $\mathrm{Si}$ layers onto the AIC-Si thin-film is a promising approach to fabricate the low-defect $\mathrm{Si}$ layers on glass substrates. ${ }^{16,17}$

Based on these findings on AIC-Si, ${ }^{13-15}$ we recently investigated the AIC of amorphous $\mathrm{Ge}(\mathrm{a}-\mathrm{Ge})$ on quartz glass substrates. As a result, we achieved preferentially (111)-oriented $(\sim 68 \%)$ poly-crystalline Ge (poly-Ge) by thinning both $\mathrm{Ge}$ and $\mathrm{Al}$ layers (50-nm thickness). ${ }^{18} \mathrm{Hu}$ et al. also formed the $70 \%$ (111)-oriented poly-Ge on $\mathrm{Al} / \mathrm{SiO}_{2}$ by the

${ }^{\text {a)} E l e c t r i c ~ m a i l: ~ t o k o @ b k . t s u k u b a . a c . j p . ~}$ inverted-structure AIC. ${ }^{19}$ Here, this paper investigates the AIC of a-Ge on insulators focusing on the annealing temperature and the $\mathrm{AlO}_{\mathrm{x}}$ interlayer formation process. The (111)orientation fraction of the grown Ge layer reaches as high as $99 \%$ in a low temperature process $\left(325^{\circ} \mathrm{C}\right)$.

In the experiments, $\mathrm{Al}$ films were first prepared onto quartz glass $\left(\mathrm{SiO}_{2}\right)$ substrates. Subsequently, the samples were exposed to air [air-exposure-time $\left(t_{\mathrm{air}}\right): 1-30 \mathrm{~min}$ ] to form native $\mathrm{AlO}_{\mathrm{x}}$ layers as diffusion control layers. After that, a-Ge films were deposited. The thickness of $\mathrm{Al}$ and a-Ge layers was determined to be $50 \mathrm{~nm}$, because this thickness is favorable for the preferential (111)-orientation. ${ }^{18}$ All the depositions were carried out at room temperature using a radio-frequency magnetron sputtering method. Finally, those samples were annealed [annealing-temperature $\left(T_{\mathrm{a}}\right)$ : 325$375^{\circ} \mathrm{C}$ ] in $\mathrm{N}_{2}$ for $10-400 \mathrm{~h}$. This sample preparation is schematically shown in Fig. 1. Nomarski optical microscopy, energy dispersive $\mathrm{x}$-ray (EDX) analysis, and $\theta-2 \theta \mathrm{x}$-ray diffraction (XRD) measurement were used to evaluate, respectively, the surface morphology, elemental composition, and crystal state of the Al-induced crystallized Ge (AIC-Ge). Cross-sectional structures of the AIC-Ge were observed by transmission electron microscopy (TEM), and the crystal orientations by electron backscattered diffraction (EBSD)

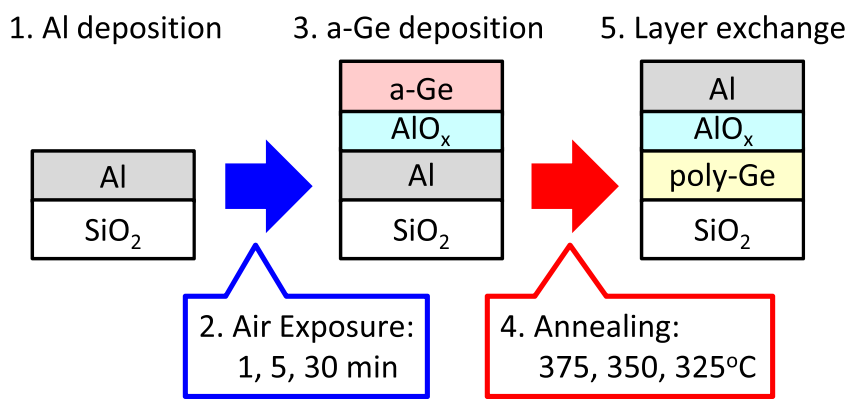

FIG. 1. Schematic structure of the sample preparation procedure. 

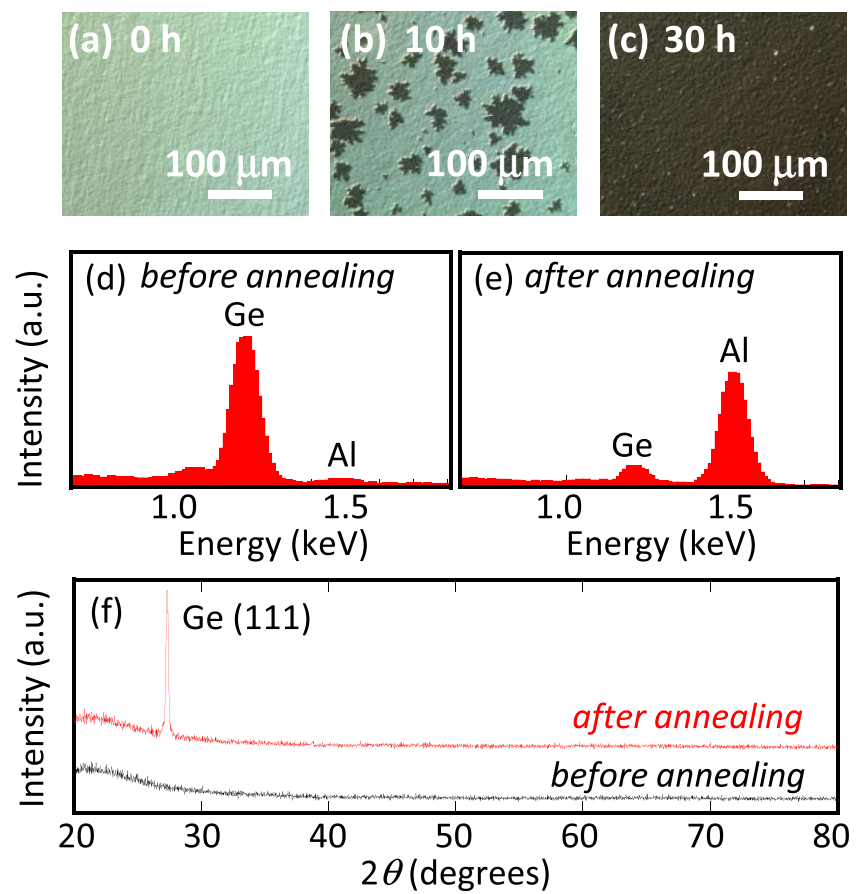

FIG. 2. Growth morphology of the AIC of a-Ge film with $t_{\text {air }}=5 \mathrm{~min}$ and $T_{\mathrm{a}}=350^{\circ} \mathrm{C}$. Nomarski optical micrographs of the back surface of the sample annealed for (a) $0 \mathrm{~h}$, (b) $10 \mathrm{~h}$, and (c) $30 \mathrm{~h}$. EDX spectra of the sample surface (d) before and (e) after annealing for $30 \mathrm{~h}$. (f) XRD patterns of the sample before and after annealing for $30 \mathrm{~h}$.

measurement. Before the EBSD measurement, we etched away the aluminum and oxide layers on the Ge layers using HF solutions (HF: $1.5 \%$ ).

Figure 2 presents the typical annealing-time evolution of the AIC process of a-Ge with $t_{\text {air }}=5 \mathrm{~min}$ and $T_{\mathrm{a}}=350^{\circ} \mathrm{C}$. Nomarski optical micrographs in Figs. 2(a)-2(c) show the back surface of the sample observed through the transparent quartz substrate. These micrographs suggest that $\mathrm{Ge}$ atoms come to the back surface, grow laterally, and cover the entire substrate during the annealing. Figures 2(d) and 2(e), respectively, show EDX spectra obtained from the sample surfaces before and after annealing $(30 \mathrm{~h})$. Here, the electron acceleration voltage was as low as $2.7 \mathrm{keV}$ for the selective detection of elements near the sample surface. These EDX spectra indicate that the upper layer changed from $\mathrm{Ge}$ to $\mathrm{Al}$ during the annealing. The XRD patterns in Fig. 2(f) show the appearance of a sharp peak after annealing. The peak at around $27^{\circ}$ corresponds to Ge (111) plane, and any other peak is not observed in the measured $2 \theta$ range $\left(20-80^{\circ}\right)$. These results indicate that the Ge layer crystallized through the layer exchange process and oriented to preferential (111) plane. The precise (111)-orientation fraction will be estimated later by means of EBSD measurements. We have demonstrated typically the completion of the AIC of a-Ge on a quartz glass substrate.

The EBSD measurement characterized statistically the crystal orientation of the AIC-Ge depending on the $T_{\mathrm{a}}$ and the $t_{\text {air }}$. Figures 3(a)-3(i) exhibit the orientation mappings of the AIC-Ge as the matrix composed of $T_{\mathrm{a}}(375,350$, and $325^{\circ} \mathrm{C}$ ) and $t_{\text {air }}(1,5$, and $30 \mathrm{~min})$. The lower $T_{\mathrm{a}}$ and longer $t_{\text {air }}$ required the longer annealing times for the completion of the AIC: (a) $10 \mathrm{~h}$, (b) $30 \mathrm{~h}$, (c) $100 \mathrm{~h}$, (d) $10 \mathrm{~h}$, (e) $30 \mathrm{~h}$, (f)

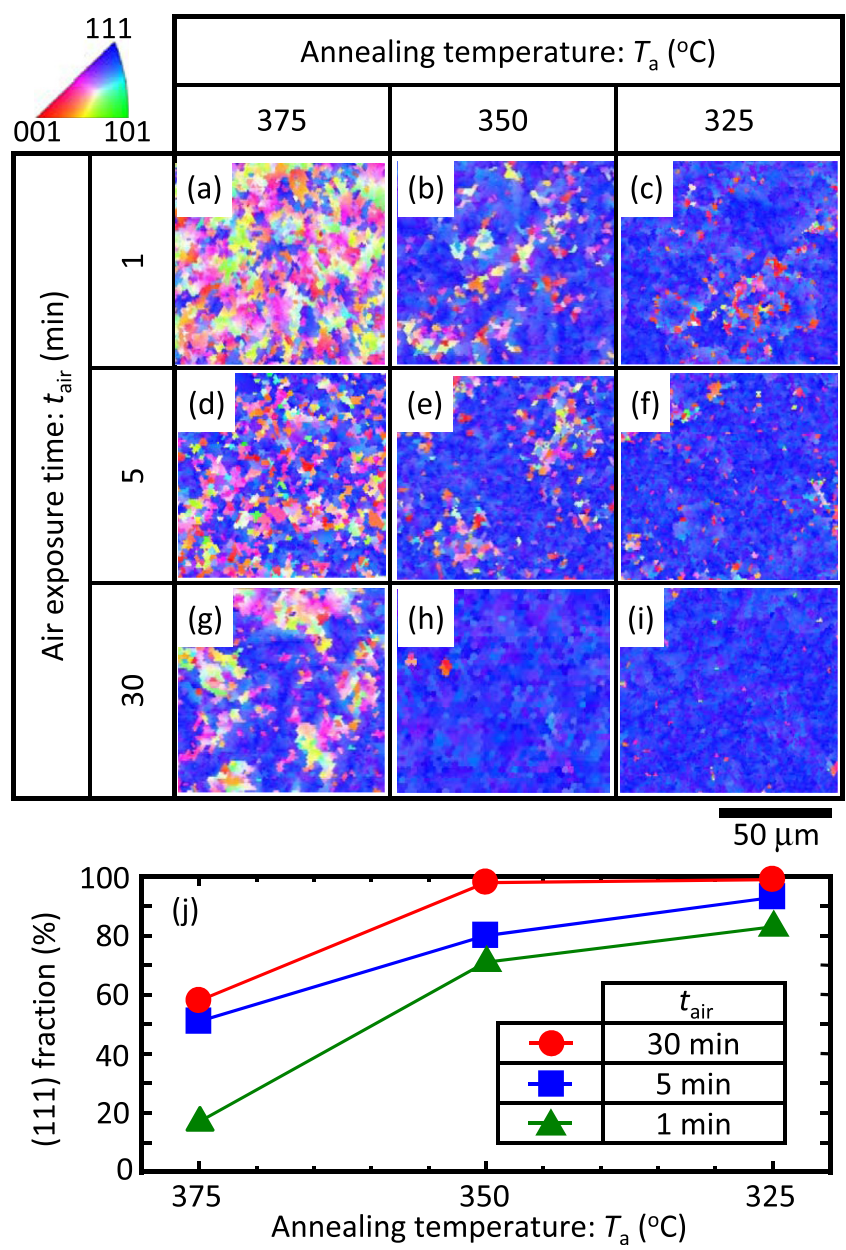

FIG. 3. (a)-(i) EBSD images of the AIC-Ge surfaces summarized as the matrix composed of $T_{\mathrm{a}}\left(375,350\right.$, and $\left.325^{\circ} \mathrm{C}\right)$ and $t_{\text {air }}(1,5$, and $30 \mathrm{~min})$; the color key corresponds to crystal orientations. (j) (111)-orientation fraction of the AIC-Ge layers depending on $T_{\mathrm{a}}$ and $t_{\mathrm{air}}$.

$100 \mathrm{~h},(\mathrm{~g}) 30 \mathrm{~h}$, (h) $100 \mathrm{~h}$, and (i) $400 \mathrm{~h}$. The AIC of a-Si had the same trend. ${ }^{13,14}$ This trend can be explained as follows: The low $T_{\mathrm{a}}$ decreases the reaction rates by the Arrhenius law ${ }^{20}$; and the longer $t_{\text {air }}$ thickens the $\mathrm{AlO}_{\mathrm{x}}$ intermediate layer thickness, and thereby reducing the interdiffusion rate of $\mathrm{Al}$ and $\mathrm{Ge}$ atoms. ${ }^{12,13}$ These orientation mappings clearly indicate that the orientation of the AIC-Ge depends on both $T_{\mathrm{a}}$ and $t_{\mathrm{air}}$ : (111) orientation becomes dominant with decreasing $T_{\mathrm{a}}$ and increasing $t_{\mathrm{air}}$. This behavior is also the same as the AIC-Si. ${ }^{13,14}$ The reason for this result can be explained as follows. The Ge nuclei occur on the $\mathrm{SiO}_{2}$ substrate because the thicknesses of $\mathrm{Ge}$ and $\mathrm{Al}$ layers are thin $(50 \mathrm{~nm}) .{ }^{18}$ Here, (111) plane has the lowest interfacial energy in the diamond structure. ${ }^{21}$ The low $T_{\mathrm{a}}$ and long $t_{\text {air }}$ provide the low-reactive rate and low-diffusion rate of $\mathrm{Ge}$ and $\mathrm{Al}$ atoms. These make it difficult to generate the other planes with high-interfacial energies, resulting in the preferential (111) orientations.

The EBSD analysis derived the area-fractions of (111) orientation from the EBSD mappings shown in Figs. 3(a)3(i), and results in Fig. 3(j). Here, the (111) fraction by definition contains the planes tilted within $10^{\circ}$ from the exact (111) plane. Figure 3(j) clearly indicates that the (111) fraction increases with decreasing $T_{\mathrm{a}}$ and increasing $t_{\text {air }}$. Note 
that the (111) fraction reaches as high as $99 \%$ by combining a low $T_{\mathrm{a}}\left(325^{\circ} \mathrm{C}\right)$ and a long $t_{\text {air }}(30 \mathrm{~min})$. In the previous report for $\mathrm{AIC}-\mathrm{Ge},{ }^{18}$ the (111) fraction was limited to $68 \%$. The main reason is found to be the high $T_{\mathrm{a}}\left(410^{\circ} \mathrm{C}\right)$. In addition, the in-plane EBSD analysis found the average grain diameter to be $110 \mu \mathrm{m}$ for this sample. These values are the highest level among the previous reports about poly-Ge layers on amorphous substrates in low-temperature processes. $^{7-9}$

Figure 4(a) displays a typical bright-field TEM crosssection of the AIC-Ge with $T_{\mathrm{a}}=350{ }^{\circ} \mathrm{C}$ and $t_{\text {air }}=30 \mathrm{~min}$, which was observed in Ge [-110] zone axis. EDX analysis was also performed along the arrowed line in Fig. 4(a), and the results were shown in Fig. 4(b). The data prove the exchange of $\mathrm{Ge}$ and $\mathrm{Al}$ layers and the uniform formation of the Ge layer over the substrate. A dark-field TEM image taken with Ge $\{111\}$ plane reflection is also shown in Fig. 4(c). The uniform bright contrast of the Ge layer indicates the single-crystal structure in this region. The selected area electron diffraction (SAED) pattern in Fig. 4(d) shows the (111)-oriented Ge. This result agrees with the EBSD measurement. A stacking fault was detected in the other region, which is presented in Fig. 4(e). This stacking fault is almost parallel to the substrate. Since (111) planes are connected with the weakest bond in the diamond structure, ${ }^{22}$ this defect is supposed to be a (111)-plane defect. The TEM-observed area $(5-\mu \mathrm{m}$ width) did not contain any other kind of defect except such (111)-plane defects; and then no defects appeared on the Ge surface. Therefore, this AIC-Ge is useful as an epitaxial template for low-defect CVD-Ge layers as well as for other advanced materials.
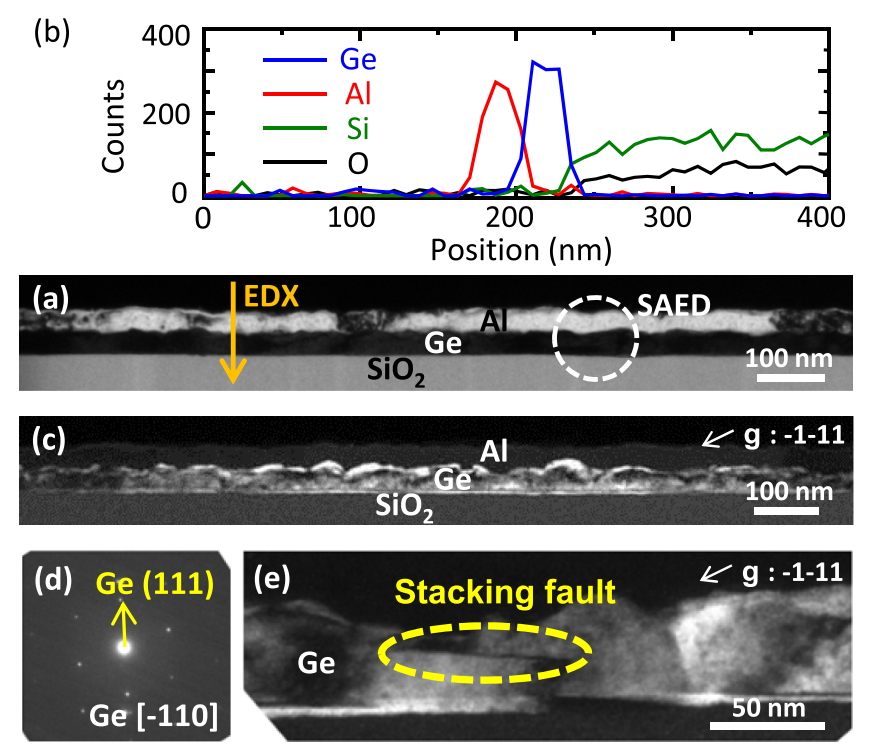

FIG. 4. Characterization of the cross-section structure of the AIC-Ge with $t_{\mathrm{air}}=30 \mathrm{~min}$ and $T_{\mathrm{a}}=350^{\circ} \mathrm{C}$. (a) Bright-field TEM image. (b) Elementarycomposition profile along the arrowed line in (a) analyzed by EDX. (c) Dark-field TEM image. (d) SAED pattern obtained at the area shown in (a). (e) Magnified dark-field TEM image.
In summary, the AIC of a-Ge was investigated focusing on the crystal orientations dependent on the $T_{\mathrm{a}}$ and the $t_{\mathrm{air}}$ for the $\mathrm{AlO}_{\mathrm{x}}$ layer formation. These parameters, $T_{\mathrm{a}}$ and $t_{\mathrm{air}}$, strongly influenced the orientations of the AIC-Ge layer: The area-fraction of (111) plane increases with decreasing $T_{\mathrm{a}}$ and increasing $t_{\text {air }}$. By combining the low $T_{\mathrm{a}}\left(325^{\circ} \mathrm{C}\right)$ and long $t_{\text {air }}(30 \mathrm{~min})$, the (111) fraction reaches as high as $99 \%$. Moreover, the cross-section TEM observation revealed the absence of defects at the Ge surface. This (111)-oriented Ge on insulators promises to be the high-quality epitaxial template for various functional materials to achieve the nextgeneration devices.

This work was partially supported by a Grant-in-Aid for Scientific Research from the Ministry of Education, Culture, Sport, Science, and Technology in Japan. Some experiments were conducted at the Nano-Processing Facility, supported by IBEC Innovation Platform, AIST.

${ }^{1}$ T. Sadoh, H. Kamizuru, A. Kenjo, and M. Miyao, Appl. Phys. Lett. 89, 192114 (2006).

${ }^{2}$ C. Y. Tsao, J. W. Weber, P. Campbell, P. I. Widenborg, D. Song, and M. A. Green, Appl. Surf. Sci. 255, 7028 (2009).

${ }^{3}$ J. Michel, J. Liu, and L. C. Kimerling, Nature Photon. 4, 527 (2010).

${ }^{4}$ T. Nishimura, C. H. Lee, T. Tabata, S. K. Wang, K. Nagashio, K. Kita, and A. Toriumi, Appl. Phys. Express 4, 064201 (2011).

${ }^{5}$ N. Fukata, K. Sato, M. Mitome, Y. Bando, T. Sekiguchi, M. Kirkham, J. I. Hong, Z. L. Wang, and R. L. Snyder, ACS Nano 4, 3807 (2010).

${ }^{6}$ K. Hamaya, H. Itoh, O. Nakatsuka, K. Ueda, K. Yamamoto, M. Itakura, T. Taniyama, T. Ono, and M. Miyao, Phys. Rev. Lett. 102, 137204 (2009).

${ }^{7}$ J. H. Park, P. Kapur, K. C. Saraswat, and H. Peng, Appl. Phys. Lett. 91, 143107 (2007).

${ }^{8}$ W. Yeh, H. Chen, H. Huang, C. Hsiao, and J. Jeng, Appl. Phys. Lett. 93, 094103 (2008).

${ }^{9}$ M. Tada, J. H. Park, J. R. Jain, and K. C. Saraswat, J. Electrochem. Soc. 156, D23 (2009).

${ }^{10}$ O. Nast, T. Puzzer, L. M. Koschier, A. B. Sproul, and S. R. Wenham, Appl. Phys. Lett. 73, 3214 (1998).

${ }^{11}$ J. Y. Wang, Z. M. Wang, and E. J. Mittemeijer, J. Appl. Phys. 102, 113523 (2007).

${ }^{12}$ A. Sarikov, J. Schneider, J. Berghold, M. Muske, I. Sieber, S. Gall, and W. Fuhs, J. Appl. Phys. 107, 114318 (2010).

${ }^{13}$ M. Kurosawa, N. Kawabata, T. Sadoh, and M. Miyao, Appl. Phys. Lett. 95, 132103 (2009).

${ }^{14}$ M. Jung, A. Okada, T. Saito, T. Suemasu, and N. Usami, Appl. Phys. Express 3, 095803 (2010).

${ }^{15}$ M. Kurosawa, K. Toko, N. Kawabata, T. Sadoh, and M. Miyao, SolidState Electron. 60, 7 (2011).

${ }^{16}$ I. Gordon, L. Carnel, D. Van Gestel, G. Beaucarne, and J. Poortmans, Thin Solid Films 516, 6984 (2008).

${ }^{17}$ B. R. Wu, S. Y. Lo, D. S. Wuu, S. L. Ou, H. Y. Mao, J. H. Wang, and R. H. Horng, Thin Solid Films 520, 5860 (2012).

${ }^{18}$ M. Kurosawa, N. Kawabata, T. Sadoh, and M. Miyao, "Enhanced interfacial-nucleation in Al-induced crystallization for (111) oriented $\mathrm{Si}_{1-\mathrm{x}} \mathrm{Ge}_{\mathrm{x}}$ $(0 \leq x \leq 1)$ films on insulating substrates," ECS J. Solid State Sci. Technol. (in press).

${ }^{19}$ S. Hu, A. F. Marshall, and P. C. McIntyre, Appl. Phys. Lett. 97, 082104 (2010).

${ }^{20} \mathrm{P}$. Germain, K. Zellama, S. Squelard, J. C. Bourgoin, and A. Gheorghiu, J. Appl. Phys. 50, 6986 (1979).

${ }^{21}$ A. A. Stekolnikov, J. Furthmuller, and F. Bechstedt, Phys. Rev. B 65, 115318 (2002).

${ }^{22}$ S. M. Sze, Physics of Semiconductor Devices, 2nd ed. (Wiley, New York, 1981), Chap. 1, p. 11. 